\title{
Carácter bifacético del trabajo, rol del estado y procesos de acumulación en regímenes comunales. El caso de Colonia Jaime, Argentina
}

\author{
Raúl Gustavo Paz \\ CONICET /INDES/UNSE. Grupo de Investigación de Sociología Rural \\ Universidad Nacional de Santiago del Estero, Argentina \\ Email: pazraul5@hotmail.com \\ María Victoria Suárez \\ CONICET/INDES/UNSE. Grupo de Investigación de Sociología Rural \\ Universidad Nacional de Santiago del Estero, Argentina \\ Email: victoriasuarez_4@hotmail.com
}

\begin{abstract}
Resumen: El reconocimiento de la persistencia y diversidad de formas de comunalismo y su capacidad de adaptación al contexto capitalista resulta clave para problematizar el postulado marxista según el cual,el desarrollo de las fuerzas productivas disolvería la base natural comunitaria.Partiendo del estudio de Colonia Jaime, se abordará un sistema comunal como un espacio donde la articulación de formas capitalistas y no capitalistas, la condición bifacética del trabajo y la construcción de redes de colaboración con el Estado,aparecen como condiciones de posibilidad para generar procesos de acumulación.Cómo la Colonia pudo diseñar, mantener y generar estos mecanismos de desarrollo bajo un contexto modernizanteserá objetivo de este trabajo.

Palabras clave: Sistema comunal, procesos de acumulación, fuerzas productivas, Estado, alternativas de desarrollo.
\end{abstract}

\section{Bifacetic character of labour, role of the state and accumulation processes. The case of Colonia Jaime, Argentina}

\begin{abstract}
The recognition of the persistence and diversity of forms of communalism and its ability to adapt to the capitalist context is key to problematize the Marxist postulate according to which the development of the productive forces would dissolve the Community natural base. Based on the study of Colonia Jaime, a communal system will be addressed as a space where the articulation of capitalist and non-capitalist forms, the bifacetical condition of work and the construction of collaborative networks with the State, appear as conditions of possibility to generate processes of accumulation. How the Colonia Jaime was able to design, maintain and generate these development mechanisms under a modernizing context will be the objective of this work.
\end{abstract}

Key words: Communal system, accumulation processes, productive forces, 


\section{Caráter bifacetico do trabalho, papel do estado e processos de acumulação em regimes comunais. O caso da Colónia Jaime, Argentina}

Resumo: O reconhecimento da persistência e a diversidade das formas de comunitarismo e sua capacidade de adaptação ao contexto capitalista são chave para problematizar o postulado marxista segundo a qual o desenvolvimento das forças produtivas tinha de dissolver a base natural da comunidade. Com base no estudo da colônia Jaime, aborda-se um sistema comunal como um espaço onde a articulação das formas capitalistas e não-capitalista, a condição bifacetica do trabalho e a construção de redes de colaboração com o estado aparecem como condições de possibilidade para gerar processos de acumulação. O modo no qual a colônia pôde projetar, manter e gerar esses mecanismos de desenvolvimento sob um contexto de modernização será o objetivo deste trabalho.

Palavras-chave: sistema comunal, acumulação, forças produtivas, estado, alternativas de processos de desenvolvimento.

$* * *$

\section{Introducción}

El devenir histórico de las instituciones comunales agrarias ha sido una preocupación central en los estudios vinculados con la cuestión agraria, en especial en el siglo XIX donde la discusión se centraba en la necesaria transformación de la propiedad comunal hacia la propiedad privada dentro de un contexto de desarrollo capitalista pleno. Tanto para el enfoque liberal como para el marxista, aunque por causas diferentes, el régimen comunal constituía un obstáculo al desarrollo de las fuerzas productivas. Para Marx y Hobsbawn (1987), todas las formas comunales presuponían a la comunidad misma como condiciones de producción y en consecuencia correspondía necesariamente a un desarrollo limitado de las fuerzas productivas. Estos argumentos sostenían la base para pensar en la inexorable disolución del régimen comunal en el marco del desarrollo capitalista.

El sistema de las comunas aldeanas europeas (el mir ruso, la zadruga balcánica, la aldea comunitaria inglesa, el colectivismo agrario español, entre otros) conforma una estructura de relaciones sociales constituidas sobre lazos de parentesco y en la institución de propiedad colectiva de la tierra, donde el campesino es el actor social característico de tales formaciones sociales. En consecuencia, en esta polémica sobre el régimen comunal, también se ponía en discusión la cuestión campesina y el rol que debía cumplir este sujeto social agrario tradicional en el devenir capitalista (Alarcón y Prieto, 2015).

De esta forma, los estudios del siglo XIX sobre el régimen comunal europeo, quedaron fuertemente anclados a las sociedades campesinas y es 
a juicio de los autores una de las herencias teóricas más fuertes que han dejado los estudios de esa época: entender a los sistemas comunales desde las lógicas campesinas o subalternas y analizarlas como instituciones que tienen su origen en viejas estructuras agrarias.

En la actualidad, ante nuevas perspectivas conceptuales como el postcapitalismo, el debate teórico en América Latina está puesto en si tales instituciones comunales agrarias son meras supervivencias o son instituciones vivas, resilientesy capaces de generar alternativas de desarrollo(Giménez, 1991; Escobar, 2010; Acosta, 2010).

Así, la impronta puesta por parte de los estudios comunales del siglo pasado pone en el presente a las sociedades campesinas e indígenas, como punto de partida para cualquier análisis de los sistemas comunales en el actual contexto latinoamericano (Patzi Paco, 2004). También en esa misma líneaincorpora la perspectiva histórica, en cuanto plantea el rol que han jugado factores sociales, económicos y medioambientales de contextos específicos, en la significancia evolutiva de tales sistemas y sus diversas formas de sobrevivencia o resistencia (Beltrán Tapia, 2015).Para esta configuración postcapitalista, en contraste con las sociedades modernas y los actores que la componen, las sociedades indígenas y campesinas reúnen los patrones políticos, culturales, económicos, ecológicos, entre otros, que permiten la instalación de alternativas al modelo de desarrollo capitalista (Patzi Paco, 2004).Así el desarrollo del sistema comunal resulta una noción impensable dentro de cualquier perspectiva capitalista y moderna.

Colonia Jaime resulta un caso paradigmático, en cuanto desafía al menos tresde los conceptos presentados brevemente en los párrafos anteriores. El primero lo constituye la presencia deun sistema comunal que no tiene sus orígenes en procesos ancestrales; es decir que no se fundasobre la base de una comunidad indígena o campesina precapitalistacuyo nacimiento se dio en la época de la conquista. Colonia Jaime nace en el año 1932 con el aporte de numerosos adherentes, lo cual permitió laadquisición de las tierras firmando un contrato de compra de un campo regadío de 549 has. de bosque virgen en el área de riego (Departamento Robles) de la provincia de Santiago del Estero, Argentina. El segundo aspecto se relaciona con el tipo de actor social que está directamente involucrado con tal sistema comunal. Los comuneros no son ni campesinos ni pueblos originarios que desplegaron una concepción ontológica basada en las sociedades indígenas; más bien fue un conjunto de jóvenes voluntarios junto a un matrimonio venidos de una localidad de La Pampa, que se unieron a cuatro familias de Santiago del Estero que adherían a la Escuela Magnético Espiritual de la Comuna Universal para llevar adelante tal proyecto comunal. El tercer punto para destacar, es la capacidad que tuvo este régimen comunal en generar un desarrollo importante de las fuerzas productivas que le permitiócrear un proceso de acumulación considerable. Esta representación empírica pone en tensión lo que abona la economía política clásica en cuanto a que el desarrollo de las fuerzas productivas disolvería la base natural comunitaria. 
Esto último, en especial el proceso de acumulación así planteado, permite sostener desde una perspectiva empírica lo que muchos académicos esbozan desde un aspecto conceptual, en cuanto que el sistema comunal constituye un espacio social, cultural, económico y político capaz de articular formas capitalistas y no capitalistas, que con ayuda de un Estado orientado a desarrollar las potencialidades intrínsecas de tal sistema, es capaz de generar la plusvalía necesaria para sustentar una transición hacia un orden poscapitalista(García Linera, 2015; Santos y Rodríguez, 2011).

Precisamente el objetivo de éste artículo será indagar sobre qué bases se generó tal desarrollo productivo y que estrategias se desplegaron tanto al interior del propio sistema comunal como sus relaciones con el exterior. En otras palabras, cómo La Colonia pudodiseñar, mantener y generar un camino alternativo de desarrollo bajo un contexto modernizante. Poder identificar y descifrar tales mecanismos es un aporte interesante puesto que permite pensar en diseños de políticas públicas tendientes a generar caminos alternativos al planteado por el capital.

\section{Encontrando elementos para definir un régimen comunal}

Giménez (1992) define un régimen comunal agrario como un conjunto de instituciones rurales referentes a la tenencia comunal de la tierra, el aprovechamiento de los recursos comunales, la gestión colectiva de los recursos, el trabajo en común, la normativa consuetudinaria y las expresiones de identidad del grupo comunero. Para este autor, el régimen comunal no es estático sino dinámico y sus transformaciones son producto de cambios externos. Esta capacidad de adaptabilidad al entorno explicaría la perdurabilidad de estos sistemas, adquiriendo los bienes comunales un carácter multifuncional que no necesariamente responden al objetivo de autoabastecimiento sino que pueden estar conectados a los mercados. Partiendo de esta definición es posible identificar características específicas que son habituales a los regímenes comunales. La propiedad comunal de la tierra que coloca a un clan, una agrupación de parientes o un grupo de comuneros, en una relación de proximidad pudiendo hacer uso de los recursos o bienes disponibles en su interior de forma tal que no afecte su sostenibilidad. Asimismo, el intercambio de trabajo entre los miembros de la comunidad constituye una estrategia fundamental para frenar procesos como la mercantilización siendo los lazos de solidaridad, el auxilio muto, la igualdad y la fidelidad a la asociación familiar, normas intrínsecas entre los comuneros (Tomasevich, 1955 en Giménez, 1991).

La capacidad de autogobierno (asamblearias en su mayoría) es otra característica destacada por los defensores de estos modelos. Esta capacidad implica el establecimiento de normas que regulan el actuar político, económico, cultural, social. Por ejemplo los mecanismos de gestión y uso de los bienes comunes resultan fundamentales hacia el interior. Es en este sentido, que en un régimen comunal, el parentesco, la propiedad y el go- 
bierno se presentan como elementos inseparables (Patzi Paco, 2004; Ostrom,2000; Luxemburgo, 2011).

Por otra parte, el desarrollo de una economía de autoconsumoes un elemento fundamental que los aleja de las formas capitalistas. Es así que los rasgos mercantiles, cuando están presentes, se manifiestan por ejemplo en la venta de la mano de obra, en las ventas de productos en mercados específicos como las ferias o en acuerdos con intermediarios (Cowan Ros y Schneider, 2008; Lacroix y Cheng, 2014). Al respecto, Luxemburgo (2011) agrega que en las formaciones de economía natural la demanda de mercancías externas era prácticamente inexistente en tanto el objetivo de la producción era el propio consumo, no habiendo excedentes o necesidad de vender productos sobrantes.

Finalmente, Polanyi (2011) identifica en las sociedades primitivas los principios de reciprocidad,redistribución y hogar los cuales se apoyan en patrones como la simetría, la centralidad y la autarquía. El principio de reciprocidad se relaciona con el buen hacer, la artesanalidad y opera en beneficio a la familia formando parte de las relaciones sociales conectadas con el buen trabajo. La redistribución aparece asociado a la figura de un jefe común con carácter territorial mientras que el hogar consiste en la producción para el uso propio. Así, la práctica de atender las necesidades del propio hogar es un aspecto de la vida económica pero nada tiene que ver con la motivación de la ganancia o con la institución de los mercados. Desde esta perspectiva la economía está subordinada a la política, la religión y las relaciones sociales. Es así que en los regímenes comunales existe una integración más ecológica y humana de la economía en la sociedad.

Recuperando algunos de estos principios es que las posturas liberales y marxistas, señalaron algunos impedimentos del régimen comunal para el desarrollo capitalista: el autoabasto como expresiones de localismo, y aislamiento; un régimen jurídico como obstáculo para la política crediticia; formas de producción arcaica que impiden el pleno desarrollo; y la propiedad comunal de la tierra como una institución precapitalista o atrasada.

Al respecto, Karl Marx y Eric Hobsbawn en Las formaciones económicas precapitalistasafirman que en los sistemas comunales, la reproducción de las relaciones naturales o tradicionales del individuo con su comunidad tanto en relación con las condiciones del trabajo como con los individuos que trabajan con él, es el fundamento del desarrollo. Pero este desarrollo es limitado por lo cual la eliminación de ese límite desembocaría en la destrucción del régimen comunal. Esto se asocia a la postura según la cual el desarrollo de las fuerzas productivas disolvería la base natural de la comunidad. Así, procesos de individuación y separación de los medios de producción serían intrínsecos a cualquier sistema comunal en tanto la evolución de la propiedad comunal a la propiedad privada se presentaba como inevitable en un contexto de avance de la sociedad capitalista. Entonces aparece en Marx un régimen comunal rígido, tradicional que inexorablemente está condenado a desaparecer. 
Desde una perspectiva opuesta, Giménez (1991) defiende un régimen comunal flexible, donde existe un equilibrio entre individuo, familia y comunidad así como un potencial económico. Es por esto que considera que muchos de los estudios realizados sobre los regímenes comunales, no lograron explicar dos realidades: la durabilidad y la diversidadde formas de comunalismo que el autor le atribuye a la creatividad social o capacidad adaptativa del régimen comunal agrario al medio social y ecológico en el que está inserto (Giménez, 1991, p.91).

Por lo tanto, a lo largo de los apartados siguientes, partiendo de los elementos identificados es que se aborda el caso de Colonia Jaime. Un caso donde se observan principios que son específicos en un régimen comunalpero que al mismo tiempo rompe con tres ejes básicos desde los cuales se acostumbra partir en el análisis de estos modelos: 1) un sistema comunal que no encuentra sus orígenes en un pasado remoto sino que fue fundada en pleno contexto de crisis capitalista precisamente como un modelo alternativo; 2) un sujeto social agrario que no se asocia a campesinos o indígenas sino a un grupo de individuos que se identifican con una ontología que reúne principios espiritistas, comunales y agropecuarios, y 3) un desarrollo de las fuerzas productivas que le permitió generar un proceso de acumulación importante.

\section{Breve descripción de Colonia Jaime: su estructura y su funcionamiento}

Colonia Jaime está ubicada sobre la Ruta Nacional 34, departamento Robles-Santiago del Estero (Argentina), en un predio de 607 hectáreas, de las cuales 365 están ocupadas actualmente con actividades agropecuarias. La comunidad está conformada por aproximadamente 100 personas (25 familias) que viven de manera permanente en la casa comunal que cuenta con un complejo habitacional bien equipado.

Desde la fundación de la Colonia, las mujeres realizan las tareas domésticas, se organizan en turnos rotativos para la preparación de la comida teniendo como modalidad el almuerzo, cena, desayuno y merienda en forma comunal, es decir, todos comparten la mesa en un comedor de grandes dimensiones. El concepto de hogar, entendido como un grupo de personas (emparentadas o no entre sí) que comparten la misma vivienda y se asocian para proveer en común a sus necesidades alimenticias o de otra índole vital (Torrado, 1998), resulta acertado al intentar definir esta modalidad de economía doméstica. Son comuneros pero a la vez no están estructurados como familias individuales ni poseen ninguna relación de propiedad sobre los bienes de la Colonia.

Con el paso de los años, las mujeres se fueron involucrando en las tareas administrativas de la comunidad, siendo en la actualidad no sólo las encargadas de llevar adelante los quehaceres del hogar, sino también las 
actividades sociales, educativas, comerciales y de vinculaciones con otras instituciones. Son ahora la voz pública de la comunidad, siendo una de ellas la presidente actual de la institución. Tal como plantea Santos y Rodríguez (2011) resulta clave en el impulso y avance de iniciativas económicas no capitalistas la participación activa de las mujeres en un contexto de relaciones de igualdad de género.

Todas las actividades agropecuarias se realizan a partir de una organización comunal del trabajo, garantizando la disponibilidad de mano de obra en cada una de las tareas que involucran. Para esto, los hombres están organizados a partir de grupos de trabajo de entre tres y cuatro personas, cada uno de los cuales está abocado a un rubro específico con un responsable principal o jefe de la actividad. En este sentido, Van der Ploeg (2010) reconoce el potencial y las ventajas de este tipo de organización frente a una agricultura de base individual donde aparecen riesgos (de enfermedad por ejemplo o disminución de costos de supervisión) que pueden causar retrasos y efectos negativos sobre la producción a la hora de realizar tareas específicas.

El sistema de producción es ampliamente diversificado tanto en sus aspectos pecuarios como agrícolas. En el rubro pecuario se destaca la actividad ganadera con aproximadamente 200 cabezas de las cuales alrededor de 120 se mantienen rotativamente en ordeñe. La actividad porcina cuenta con 47 madres y 3 reproductores, obteniendo un promedio de 8 lechones por parto. Los lechones son destinados tanto al autoconsumo como a la venta. Para la producción de chacinados, compran capones en pie para faenarlos en las instalaciones de la comunidad, con una producción semanal de alrededor de 800 kilos (que contempla chorizo italiano, criollo y colorado, morcilla, salchicha).En cuanto a la actividad avícola, Colonia Jaime recibe aproximadamente 900 pollos híbridos por semana los cuales se encuentran en etapa de terminación. Además, dispone de unas 80 colmenas con una capacidad de producción anual de cerca de 6 tambores de miel de 330 kilos cada uno y con una importante producción de polen.

Con respecto a las actividades agrícolas, la comunidad destina una importante cantidad de hectáreas para la realización de cultivos que se utilizan como forraje para los animales (180 has de alfalfa; 50 has de maíz; 30 has de avena). Incluso, debido a la cantidad de vacunos y porcinos que se encuentran en la explotación, se compraron tierras anexas que le permitieran obtener alimento suficiente para las épocas de escasez como lo es la temporada de invierno, evitando la compra en el mercado. La huerta bajo riego por goteo es otra actividad de gran importancia en la comunidad desarrollándose sobre una extensión de 12 hectáreas con una importante diversificación en la producción (pimientos, berenjenas, brócoli, tomate, coliflor, verduras de hojas verdes, entre otras), así como cítricos y otros cultivos comerciales (cebolla, batata, melón, sandía, zapallos, entre otros).

Para la realización de muchas de estas actividades, cuenta con instalaciones equipadas, entre las cuales se destaca un tambo con ordeñadora 
mecánica de dieciséis bajadas; una sala de extracción de miel con máquinas extractoras y purificadoras; una fábrica de chacinados con aberturas y cámara frigorífica de doble propósito; una sala para el faenado de los pollos con máquina peladora y una heladera de carnicero. Un biodigestor que opera a partir del gas que se obtiene del abono de las vacas de la explotación alimentando la cocina comunal todo el año. También el fertirriego como una novedad tecnológica ha sido incorporado para el desarrollo de la huerta.

Con respecto a la comercialización, Colonia Jaime ha construido interesantes circuitos cortos de comercialización a partir del despliegue de fuertes lazos sociales con otros sujetos. El principal mercado para la comunidad lo constituyen sus dos bocas de expendio ubicadas en una de las ciudades más importantes de la provincia donde centraliza gran parte de su producción. Son administrados y atendidos por los mismos comuneros, hombres y mujeres, representando más allá de lo comercial, un espacio social donde emergieron importantes vínculos.Además, diseñaron un circuito comercial donde se realizan viajes hacia distintas localidades del sur de la provincia en un camión de su propiedad, trasladando productos hortícolas y agrícolas que se generan en el predio y regresando con capones en pie para faenarlos en la Colonia.

Finalmente, en cuanto a la organización institucional de Colonia Jaime, a partir del año 2004 la comunidad se vio obligada a adoptar la figura de Asociación Civil sin fines de lucro, pues desde la década del '90 la comunidad arrastraba un problema impositivo con AFIP, órgano recaudador de impuestos. Entonces como primera medida de solución del conflicto la comunidad adoptó el nombre de Asociación Civil Colonia Jaime. Está regida por un Estatuto reconocido por el Estado Provincial; la Asamblea General de Miembros es el órgano social que representa la autoridad máxima y en la cual descansa la voluntad soberana de la entidad. Asimismo el Consejo Directivo dirige, administra y ejerce la representación de la entidad.

La Colonia maneja la economía destinando todos los ingresos a un fondo común, con lo cual se cubren las necesidades institucionales que incluyen aquellos gastos destinados a la educación dentro de la comunidad (compra de material didáctico, insumos varios), el mantenimiento de la infraestructura (salón de estudio, salón de computación) y los gastos de las actividades productivas (maquinarias, herramientas, insumos, etc.). A su vez, cubre todas las necesidades básicas de los miembros en vivienda, alimentación, salud, vestimenta, educación primaria, secundaria y universitaria o terciaria. En palabras de los comuneros,

"el asociado a partir del momento en que forma parte de la comunidad renuncia a toda retribución de dinero en forma de salario u otro bien que no sea el indispensable para su subsistencia y la de su familia, siendo también libre de dejar la asociación en el momento que desee no pudiendo reclamar ningún bien desde el momento que reconoce que la institución es la única propietaria de todos los bienes materiales” (Palabras de comunera). 
Los conceptos de Polanyi (2011) sobre la simetría, reciprocidad y centralidad quedan materializados en esa expresión.

\section{Frases que explican la filosofía de la Colonia}

Colonia Jaime fue fundada en el año 1932 por un filósofo español llamado Joaquín Trincado (1866-1935) bajo los principios doctrinarios del Espiritismo Luz y Verdad. Una revisión de sus postulados remite a una línea de pensadores, conocidos como Socialistas Utópicos (Saint-Simón; Robert Owen; Charles Fourier), que desde el surgimientos del capitalismo diseñaron modelos de organización social y económica alternativos donde lo colectivo, la solidaridad y la reciprocidad son los principios rectores. Trincado consideraba que la humanidad debía evolucionar hacia la Gran Comuna de Amor Universal sin parcelas y sin fronteras donde se acabaría con la supremacía y la autocracia; se terminaría con las desigualdades sociales, económicas y políticas; el hombre se liberaría de las cadenas de la esclavitud y toda forma de explotación declarándose como ley el trabajo productivo abandonándose el trabajo inútil (Trincado,1975 [1934]).

Fue así que Colonia Jaime se constituyó como el primer núcleo comunal organizado sobre las bases de la Doctrina del Espiritismo Luz y Verdad, acuñado por Trincado, dando comienzo al ideal de fraternidad y comunización de la familia humana.

A continuación se destacan algunos de los conceptos que definen y caracterizan elrégimen comunal extrayendo fragmentos de algunos de los libros de Trincado, de revistas de la Escuela Magnético Espiritual de la Comuna Universal,del Reglamento Interno y del Estatuto de Colonia Jaime y también de la propia voz de los comuneros. Esta reconstrucción así como el trabajo en su conjunto pudo ser posible a partir de un arduo trabajo de campo que implicó la convivencia con el grupo de comuneros, la realización de entrevistas en profundidad, observación participante y un importante trabajo de archivo en la biblioteca de la comunidad.

- Lo Comunal representa todo el producto del trabajo manual y de la inteligencia y con la instauración de la Comuna cada uno estaría obligado a producir cuanto más pueda, en todo lo de la agricultura, las artes y las industrias, para el mayor bienestar.

- En la Comuna, los hombres, en los dos sexos y en todas las edades, componen el valor nominal, siendo secundarios todos los demás valores que pueda tener.

- En la Comuna debe regir la Igualdad entre todos los individuos por lo cual cada individuo, recibirá lo necesario a su subsistencia, en toda variedad de artículos en crudo, y en lo referente a la vestimenta, muebles y útiles. 
- El dinero no tiene ningún valor en la comuna pero sí, al igual que el representativo en otras naciones para cumplirse mutuamente y cambiarse productos.

- Una colonia comunal es un proyecto de vida en común donde un grupo de familias decide voluntariamente abandonar su aislamiento para compartir con otros su trabajo, su esfuerzo, la educación de sus hijos, con el fin de realizarse individualmente a través del bienestar y la prosperidad de todos.

- Una colonia elimina la propiedad privada de los individuos. La vida comunal demuestra que la persona humana puede satisfacer todas sus necesidades sin poseer bienes ni estar apegada a lo que la civilización consumista contemporánea considera como elementos indispensables para la felicidad

- La Colonia se forma con tres clases de capital: A: Capital promotor: Dinero; B: Capital de utilidad: hacienda, maquinaria y herramientas en general; C: Personas

- El trabajo productivo es sólo lo que regenera a los hombres y los prepara en aquellas condiciones para deponer antagonismos y gozar de la verdadera fraternidad.

- El modelo que nosotros vivimos y que en realidad encarnamos tiene como consecuencia la producción pero el eje y la causa que lo mantiene es mostrar un modelo de vida diferente, donde el ser humano es el principal protagonista(comunero).

Son estos conceptos, principios que estructuran una filosofía de vida en común puestos en práctica en la vida cotidiana de Colonia Jaime. En ellos queda expresado el ideal de un gobierno amparado en la justicia, la igualdad, la fraternidad y la reciprocidad que se impulsa además, a partir de la construcción de una relación dinámicaentre mercado, Estado y comunidad.

\section{La condición bifacética del trabajo y los circuitos cortos como estrategias de acumulación}

No hay duda de que Colonia Jaime es un sistema comunal agrario. La tenencia comunal de la tierra, la vida en comunidad, la gestión mancomunada de los recursos, una identidad y objetivos comunes por las personas que la habitan junto al trabajo en común, son sus principales características. Pero además de ser un régimen comunal, la Colonia tiene otros valores intrínsecos que guardan cierta relación con el mundo campesino y la agricultura familiar, al momento de relacionarse con la producción agropecuaria y los mercados. En Colonia Jaime el aporte de mano de obra es comunal 
pero también es no asalariada que junto a la intensificación del trabajo, estructuran tanto los procesos sociales, económicos y productivos dentro de la explotación.

Colonia Jaime puede ser considerada como una unidad domésticoproductiva donde la vida económica tiene un carácter doble y complementario. Por un lado, la producción se orienta a cubrir las necesidades de consumo de la familia comunal; por esa misma razón dicha producción presenta un alto grado cualitativo, en términos de proveer el producto adecuado tendiente a cubrir dichas necesidades. Esta producción tiene cualidades específicas que se hacen efectivas al momento del consumo o del uso. La satisfacción de tales necesidades no puede ser cuantificada desde las categorías económicas clásicas, sino más bien desde una perspectiva cualitativa de suficiencia e insuficiencia y sus distintos grados en relación a la capacidad de cubrir tales necesidades.Por otro lado la economía familiar comunal, al estar interactuando fuertemente con el mercado, incorpora las dimensiones del intercambio y la mercantilización; la producción entonces cobra una cierta relevancia en términos de cantidad y comienza a ser independiente de las necesidades de la unidad doméstica, para orientarse y responder alas lógicas del mercado.

En ese carácter bifacético de la vida económica de la agricultura comunal familiar, existe una dualidad entre esas dos lógicas productivas y en consecuencia una permanente tensión según los momentos históricos del desarrollo en el interior de la Colonia, imprimiéndole una lógica particular que debe ser interpretada de acuerdo al contexto temporal y espacial. Allí la producción que se orienta para la subsistencia debe ser pensada desde la economía de las cosas en especie (in natura), mientras que la producción que se orienta al mercado, se convertiría en valores de cambio, y el proceso de producción tendría una segunda forma de existencia que es en valor (in valore) (Chayanov, 1987). Sin embargo, la producción en la agricultura comunal familiar, al igual que en el mundo campesino y de la agricultura familiar, es indivisible y no resulta claro poder establecer su dirección hacia el consumo o al mercado.

Así, la producción en la unidad doméstico-productiva comunal, presenta un doble modo de existencia, resultado del trabajo no asalariado de sus propios miembros. Esa tensión entre la producción in naturaein valore, sólo puede estar resuelta por el carácter también bifacético de la mano de obra familiar, ya que el trabajo aplicado y que da lugar a la producción, suele ser indivisible.

En algún momento y por distintas circunstancias, la fuerza de trabajo familiar se orientará en mayor grado hacia la producción de valores de uso y en otros hacia la creación de valores de cambio pero siempre en coexistencia. Un aspecto más que le otorga mayor complejidad en relación a esa condición bifacética de la mano de obra familiar comunal, es que dicha fuerza de trabajo se orientará a desarrollar los objetos de trabajo y los instrumentos de trabajo, muchos de los cuales participarán tanto en el sis- 
tema in natura como in valore, tendientes a incrementar los rendimientos y la productividad que serán destinados a la producción de valores de uso y de cambio (Marx y Hobsbawn, 1987; Van der Ploeg, 2013).

Así, en algunos momentos de la historia de Colonia Jaime la producción in valore marcó las decisiones económicas de la comunidad generando una profunda crisis y afectando la sobrevivencia del modelo. Desde sus inicios, Colonia Jaime se orientó hacia una agricultura extensiva con cultivos tales como maíz (40 has), trigo (80 has) y alfalfa (45 has). La fuerte presencia de intermediarios, dependencia del mercado de insumos, la búsqueda de créditos orientados al proceso productivo y la ampliación de escala fueron requerimientos de los cuales no podían escapar. Además, entrada la década del '70 se incorporó el algodón (100 has) como otro cultivo extensivo, donde aparte de las características anteriores implicó también ser tomadores de precios pues la cooperativa algodonera de la provincia era el principal comprador.

Es en ese contexto donde la fuerza de trabajo comunal familiar perdió su vital importancia como elemento ordenador en el proceso de acumulación, siendo el punto crítico el período de 1970 a fines de 1980, donde el sistema in valore con sus categorías económicas clásicas, llegó a apoderarse del natural proceso de producción e instaló una lógica económica en función de la teoría clásica del valor. Con palabras de Wood (2012), se fueron instalando los imperativos del mercado, los cuales obligaron a la Colonia a volverse más dependiente de los mercados y a responder a la lógica de la ganancia y al aumento de la competitividad a partir de la inversión y el crédito.

Fue sin dudas el momento más difícil para la Colonia, con fuerte endeudamiento y procesos de descapitalización muy acentuados, marcado también por los fuertes éxodos de comuneros que venía arrastrando la comunidad desde finales de la década del '50 resultado de las crisis recurrentes y los temores por la inviabilidad del modelo. Es en esos instantes que a ojos de Polanyi (2011) el manejo económico de la Colonia se desarraigó de las condiciones y necesidades de los propios comuneros: "en lugar de que la economía se arraigue en las relaciones sociales, éstas son las que se arraigan en el sistema económico” (Polanyi, 2011, p. 27).

Es en este momento donde los comuneros, luego de profundas discusiones, toman la decisión de salir a la búsqueda de mercados que puedan ser gobernados por ellos mismos. Es entonces cuando se decide redireccionar la estrategia productiva y se apuesta fundamentalmente a la reconversión del sistema hacia la diversidad, desarrollo y consolidación del sistema pecuario.

Dos aspectos estuvieron dando vueltas en la nueva estrategia, fruto de la experiencia obtenida de esos años. El primero estuvo ligado a desplegartoda la potencialidad que estaba presente en esa condición bifacética de la mano de obra comunal. Cultivos como el algodón demanda- 
ban una cantidad importante de mano de obra pero sólo en momentos de cosecha, lo cual requería contratar mano de obra asalariada externa, además de ser una actividad que no demanda trabajo creativo, artesanal y permanente que pudiera generar objetos e instrumentos de trabajo orientados a mejorar la eficiencia productiva (Van der Ploeg, 2013).

Precisamente la producción pecuaria en general, requiere de un uso intensivo y cotidiano de mano de obra (manejo alimenticio, cuidado sanitario, mejora genética y obtención de objetos e instrumentos de trabajo) que no siempre puede ser reemplazada eficientemente por la mecanización. El incremento de valor agregado a partir de procesos agroindustriales (de la leche al queso, del cerdo a los embutidos, etc.), el efecto de recurso vinculante con el sistema productivo en general (el estiércol como insumo para los cultivos hortícolas y producción de gas para consumo doméstico a partir de un biodigestor; cultivos como maíz y alfalfa que se orientan en parte a la alimentación de los animales bajando la externalización), la producción de nuevos objetos de trabajo a partir de objetos de trabajo ya presentes (un animal que da leche pero también la cría que con un cuidado en su selección y manejo entrará oportunamente en el proceso productivo), son otras de las características de la producción pecuaria que permiten desplegar esa condición bifacética del trabajo comunal familiar.

Esta forma de trabajo, de hacer como lo llama Holloway (2011) crea un tipo de capital diferente. A partir del trabajo no asalariado se construye un capital comunal y dicho capital difiere del capital clásico en cuanto no está gobernado por el mercado de capitales. Nuevamente el trabajo útil aparece como generador de valores de uso que en el ciclo productivo pueden transformarse en valores de cambio como también en capital patrimonial. En este marco, el trabajo comunal familiar constituye el principal mediador de la circulación material entre la naturaleza y el hombre. De esa forma, la artesanalidad, el saber hacer y el conocimiento práctico sobre la naturaleza, aspectos comunes en la agricultura familiar, constituyen formas de intensificación del trabajo familiar orientado en hacerun buen producto (Paz et al., 2011; Rodríguez,et al., 2015). Tal producto no está definido por la cantidad de trabajo necesario para producirlo, sino más bien por su valor cualitativo en cuanto se orienta a un fin en particular de la familia. Desde ésta perspectiva las actitudes de reciprocidad y solidaridad, de ayuda mutua, el orgullo del comunero en el ejercicio de su oficio, la satisfacción del elogio público por hacer un producto de calidad, el desarrollo de habilidades diferentes a las exigidas por el mercado y la protección de la naturaleza, son aspectos que se vinculan con formas de organización económica dentro del capitalismo pero basadas sobre los imperativos de la agricultura familiar comunal con principios no capitalistas.

El segundo aspecto se relaciona con la necesidad de gobernar al mercado vinculado con la producción. Los comuneros a partir de sus historias de vida han comprendido que existen fuertes asimetrías y procesos de extracción de excedentes, cuando con sus productos se relacionan a mercados donde no pueden tener ningún control y menos aún ser generadores 
de precios o al menos tener una influencia en la determinación del valor monetario de sus productos. Evitar la intermediación fue uno de los principales objetivos en la comercialización de su producción y la conformación de las dos granjas comerciales fue su principal maniobra de venta. Los circuitos cortos son una estrategia de resistencia que se sostiene y gana identidad a partir de otras condiciones que están presentes en la Colonia Jaime. La artesanalidad, el saber hacer orientado a la generación de valor agregado, volúmenes de producción de escalas manejables, flexibles, con productos de calidad y a un precio justo son dimensiones que se encuentran en sintonía con los mercados que vienen construyendo.

\section{Los procesos de acumulación, desarrollo de las fuerzas productivas y el rol del Estado}

Para Marx y Hobsbawn(1987) la finalidad del trabajo comunal no es la creación de valor sino más bien la conservación de la propiedad y de toda la comunidad. En Colonia Jaime esto no ocurre, el trabajo se orienta a la creación de valor a través de la producción de bienes de consumo y de mercancía sin que exista producción de plusvalía. Esta creación de valor le ha permitido generar una instancia de acumulación que se sustenta sobre la base del carácter bifacético de la mano de obra comunal, la ausencia del salario y de un cierto nivel de dominio de la naturaleza por parte de los comuneros. Para que la apropiación real del proceso de trabajo comunal no sea baja e instale desde el principio un desarrollo limitado que seguramente la llevará a la ruina, se requiere el aumento de la productividad del trabajo que se logra a partir del desarrollo de las fuerzas productivas.

En otras palabras, aunque la primera gran fuerza productiva es la comunidad misma, ella requiere del desarrollo tecnológico para pasar de una economía de subsistencia a una economía incluso de gran escala que conceda un ingreso económico comunal que le permita acumular. Esto fue comprendido por los comuneros y desde el seno mismo del Consejo se orientaron acciones de vinculación con el Estado, a los efectos de solicitar asesoramiento y también apoyo financiero para introducir innovaciones tecnológicas tanto en el proceso de producción primaria como de industrialización de los productos primarios. Esta perspectiva por parte de Colonia Jaime va en línea con las manifestaciones de Patzi Paco (2004) cuando expresa que sin duda, la constitución de las empresas comunales necesita de una especie de acumulación originaria, eso significa que por una parte el Estado más que prestar dinero a la población debe otorgarle tecnologías para que estas asociaciones comunales puedan emprender como trabajadores directos.

Muchos son los ejemplos de vinculación con el Estado pero a juicio de los autores tres son más emblemáticos con respecto al otorgamiento de subsidios para la adquisición de equipamiento que supone una inversión para la mejora, continuidad y sustentabilidad del modelo. 
El primero está dado por la incorporación delbiodigestor, actualmente único en la provincia, bautizado por los colonos con el nombre de Don Felipe, el cual utiliza las excreciones de los animales para producir gas que es usado como combustible en la cocina comunal. También impacta en el sistema agroecológico en su conjunto, al minimizar el consumo de leña evitando la degradación del monte, disminuyendo la contaminación de los vectores que afectan a personas y animales y buscando que el agua tratada sea reutilizada para el sistema de riego destinado a los campos de la colonia. El proyecto fue desarrollado en el año 2011 por el Instituto Nacional de Tecnología Industrial (INTI), con la participación de la Universidad Nacional de Santiago del Estero y es financiado por la Subsecretaría de Desarrollo, Ciencia y Tecnología y Gestión Pública del Gobierno de la provincia de Santiago del Estero con fondos propios.

La otra incorporación, fue en el año 2012 y lo constituye la fábrica de chacinados que recibió aportes del Estado provincial a los fines de instalar una moderna planta de elaboración con cámara frigorífica de doble propósito. Cuenta con una sala de elaboración con su equipamiento completo, cámara frigorífica con una capacidad de 60 medias reses porcinas y para producto elaborado con una capacidad operativa para unos $300 \mathrm{~kg} /$ diario. Por su parte el Ministerio de la Producción brindó asesoramiento técnico permanente durante todo el proceso de proyecto y ejecución de la obra. El resto de la infraestructura que compone esta fábrica fue realizado y financiado por la propia comunidad.

Finalmente, el tercer ejemplo lo compone la ampliación del riego por goteo. Su principal objetivo es mejorar la producción, mediante la aplicación de nuevas tecnologías y asimismo obtener productos imprescindibles en la dieta nutritiva de los beneficiarios, como así también promover la actividad fruti-hortícola con un paquete tecnológico acorde a términos de eficiencia y productividad. Se firmó un Convenio de Cooperación para Asistencia Técnica y Capacitación de Fomento y Desarrollo del Sistema Fertirriego entre la Secretaria de Desarrollo, Ciencia y Tecnología de la Provincia y la Colonia Jaime. Dicho convenio permite articular acciones con otros sectores productivos afines, en el marco de los sistemas de innovación, tecnología para favorecer el desarrollo de la producción primaria y agroindustrial y de gestión en la región. Por otra parte también se firmó un Convenio Marco de Cooperación y Asistencia Recíproca entre el Ministerio de Producción de la Provincia y la Colonia Jaime, teniendo como objetivo profundizar el proceso de cooperación existente entre las partes en el orden educativo y productivo, brindando asistencia técnica recíproca y financiera, fortaleciendo los procesos de capacitación de productores en general y de tecnificación en la producción. Por otro lado,Colonia Jaime recibió distintas propuesta desde feedlot, circuitos de turismo rural, integrarse a grandes cadenas de supermercados, entre otros. Sin embargo fueron rechazadas porque no respondían a su filosofía comunal que apunta a promover acciones productivas, educativas, científicas, culturales y sociales sobre las bases de la vida en comunidad. Una de las propuestas más recurrente fue la posibilidad de exportar productos que se generan en la 
comunidad. Pero los comuneros manifiestan tener en claro que esto significaría aumentar los volúmenes de producción, ampliar la extensión de tierras dedicadas a cultivos comerciales, aumentar el grado de externalización y una mayor subordinación a los mercados y sobre todo generar una sobrecarga en la mano de obra comunal y comenzar un fuerte proceso de asalarización.

Tres son las reflexiones que surgen de analizar los distintos ejemplos. La primera tiene que ver con la incorporación y utilización de los avances tecnológicos y del conocimiento de la sociedad moderna pero tal adopción está subordinada a la lógica comunal que queda establecida previamente a partir de la discusión en el interior del Consejo (Escobar 2010). Aquellas propuestas tecnológicas que fueron apropiadas por los colonos tiende a generar un importante desarrollo de las fuerzas productivas, incrementando la productividad y la eficiencia sin que ello implique cambios profundos al interior del propio sistema comunal. Una frase de Patzi Paco (2004) refleja lo expuesto cuando dice "El sistema comunal se puede apropiar del entorno liberal sin que esto implique la transformación del sistema...” (Patzi Paco, 2014, p. 176). Esto es lo que viene sucediendo en los últimos tiempos en la Colonia Jaime.

La segunda reflexión se relaciona con el rol del Estado, un estado liberal que ha venido actuando de catalizador e incluso como creador de propuestas tecnológicas que son transformadas al interior de la Colonia como alternativas contrahegemónicas. El éxito de tales alternativas se basó principalmente en la construcción en redes de colaboración y apoyo mutuo entre colonos e instituciones del Estado pero también en la capacidad de un sistema comunal que supo tomar lo "bueno del modelo modernizante" para asimilarlo a una visión comunal, donde la lógica capitalista perdió su centralidad.

Finalmente la tercera reflexión está en relación con el rol activo de los comuneros y su capacidad de toma de decisiones respecto a qué recibir y qué rechazar, a partir de los objetivos construidos en forma colectiva. En este sentido, cobran relevancia las palabras de Acosta (2010) cuando afirma que el "éxito o fracaso no es sólo una cuestión de recursos físicos sino que depende decisivamente de las capacidades de organización, participación e innovación” (Acosta, 2010, p.26). Los comuneros de Colonia Jaime asumen un rol activo en la conducción de su unidad productiva, siendo ellos quienes tienen la última palabra. Sin embargo éstas relaciones entre el desarro$1 l o$ e implementación de tecnologías y el Estado son ambiguas y multifacéticas.

Es interesante cerrar este artículo con un discurso del Gobernador de la provincia al momento de dar por inaugurado la fábrica de chacinado:

“Es un ejemplo lo que estamos viendo, de aplicar con la ayuda del INTI, de los Ministerios respectivos que han trabajado y de la gente que produce alimento el conocimiento que aplica una tecnología que 
da mayor calidad y mayor posibilidad de valor y de crecimiento económico. Pero también lo más importante, y que da el ejemplo de la Colonia Jaime, es cómo podemos trabajar desde el Estado Nacional, el Estado Provincial, los Estados Comunales y podemos hacer que la gente que tiene ganas, amor por las cosas y sabe hacer, darle el acompañamiento... y así lo hacemos con todas las Instituciones de la Provincia, que tienen ganas de hacer cosas y cuando éstas cosas van de la mano, de la generación de trabajo y de tecnología a través del conocimiento, estamos hablando de la economía real" (Palabras del Gobernador de la provincia de Santiago del Estero). 


\section{Bibliografía}

Acosta, A. (2010).El Buen Vivir en el camino del post-desarrollo. Una letura desde la Constitución de Montecristi.Quito, Ecuador: Fundación Friedrich Ebert.

Alarcón, S, y Prieto, V. (2015). KarlMarx Escritos sobre la Comunidad Ancestral.La Paz, Bolivia: Fondo Editorial y Archivo Histórico de la Asamblea Legislativa Plurinacional.

Beltrán Tapia, F. (2015). Social and Environmental Filters to Market Incentives: The Persistence of Common Land in Nineteenth-Century Spain.Journal of Agrarian Change,(Reino Unido), (15),239-260. doi: 10.1111/joac.12056

Chayanov, A. V. (1975). Sobre a teoría de los sistemas económicos no capitalistas. Cuadernos Políticos, (Distrito Federal), 5, 15-31. Recuperado de: http://www.bolivare.unam.mx/cuadernos/cuadernos/contenido/CP.5/CP5.5AlexanderVChayanov.pdf

Cowan Ros, C., y Schneider, S. (2008).Estretagias campesinas de reproducción social. El caso de las Tierras Altas de Jujeñas, Argentina.Revista Internacional de Sociología, (Madrid), 60(50),163185.doi: http://dx.doi.org/10.3989/ris.2008.i50.100.

Escobar, A. (2010). América Latina en una encrucijada: ¿modernizaciones alternativas, posliberalismo o posdesarrollo?. EnV. Bretón (Ed,), Saturno devora a sus hijos. Miradas críticas sobre el desarrollo y sus promesas(30-85). Barcelona, España:Icaria.

García Linera, Á. (2010). La forma comunidad del proceso de producción. Formas comunales que han precedido al régimen del capital: Algunas determinaciones de forma y contenido técnico-organizativo. Buenos Aires, Argentina: Prometeo.

Gimenez, C. (1991).Permanencia y funcionalidad del régimen comunal agrario en España y México. Madrid, España:Ministerio de Agricultura, Pesca y Alimentación.

Holloway, J. (2011).Agrietar el capitalismo. El hacer contra el trabajo.Buenos Aires, Argentina: Herramienta.

Lacroix, P.y Cheng, G. (2014).Ferias y Mercados de Productores: Hacia nuevas relaciones campo-ciudad.Lima, Perú: Centro Peruano de Estudios Sociales.

Luxemburgo, R. (1978).La acumulación de capital.Barcelona, España: Ediciones Grijalbo. 
Marx, K., y Hobsbawn, E. (1987).Formaciones Económicas Precapitalistas.D. F., México: Siglo XXI.

Ostrom, E. (2000).El Gobierno de los Bienes Comunes: La evolución de las instituciones de acción colectiva.D. F., México: Fondo de Cultura Económica de México.

Patzi Paco, F. (2004).Sistema comunal. Una propuesta alternativa al sistema liberal.La Paz, Bolivia: CEA.

Paz, R., Rodriguez, R., Gonzalez, V., y Lipshitz, H. (2011). Producción Económica en una Pequeña Explotación Lechera Caprina: Hacia unDiseño Alternativo de Desarrollo Rural.Revista Asociación Latinoamericana de Producción Animal,(Maracay), 18(3-4), 97-111.Recuperado de: http://www.produccion-animal.com.ar/ produccion_caprina/leche_caprina/35-18vol3-4_Paz.pdf

Polanyi, K. (2003).La gran transformación: los orígenes políticos y económicos de nuestro tiempo. D. F., México: Fondo de Cultura Económica.

Rodriguez, R., Paz, R., Suarez, V., y Diaz, J. (2015). Construyendo mercados desde la propia finca. Tres experiencias en la agricultura familiar,Agro Sur,(Valdivia), 43(1), 3-17.doi:10.4206/ agrosur.2015.v43n1-02

Santos, B. d. (2011).Producir para vivir. Los caminos de la producción no capitalista.D. F., México:Fondo de Cultura Económica.

Santos, B., y Rodriguez, C. (2011).Introducción. Para ampliar el canon de la producción.En B. Santos (Coord.), Producir para vivir. Los caminos de la producción no capitalista,(pp. 15-61). D. F. México:Fondo de Cultura Económica.

Tomasevich, J. (1955).Peasants, politics and economic change in Yugoeslavia.Londres, Inglaterra: Stanford University Press.

Torrado, S. (1998).Familia y diferenciación social: cuestiones de método.Buenos Aires, Argentina: EUDEBA.

Trincado, J. (1965).Filosofía Austera Racional.Buenos Aires, Argentina: López.

Trincado, J. (1975).Código de Amor Universal. Para el régimen de la Comuna de Amor y Ley.Buenos Aires, Argentina: Impresos Laflor.

Van der Ploeg, J. (2010).Nuevos campesinos. Campesinos e imperios alimentarios.Barcelona, España: Icaria. 
Van der Ploeg, J. (2013).Peasants and the art of farming. A Chayanovian manifesto. Canadá: Agrarian Change and Peasant Studies Series, Fernwood Publishing.

Wood, E. M. (2012). Peasants and the market imperative: the origins of capitalism.EnH. Akram-Lodhi y C. Kay (Eds.), Peasants and Globalization (37-56).Londres, Inglaterra: Routledge

Recibido:14.03.17

Aceptado: 09.01.18 